\title{
Efeito da ultrasonicação da sílica ativa e da nanossílica coloidal em pastas de cimento
}

\author{
Ultrasonication effect of silica fume and \\ colloidal nanosilica on cement pastes
}

\author{
Yuri Sotero Bomfim Fraga ${ }^{1}$, João Henrique da Silva Rêgo ${ }^{1}$ \\ Valdirene Maria Silva Capuzzo ${ }^{1}$, Daniel da Silva Andrade ${ }^{2}$
}

\footnotetext{
${ }^{1}$ Programa de Pós-graduação em Estruturas e Construção Civil - PECC/UnB CEP: 70910-900, Brasília, DF, Brasil.

${ }^{2}$ Departamento de Ciências Exatas e Tecnológicas - CCET/UEG CEP: 75132-903, Anápolis, GO, Brasil.

e-mail: yurisotero.engcivil@gmail.com; jhenriquerego@unb.br; valdirenemaria@unb.br; ds.andrade@hotmail.com
}

\begin{abstract}
RESUMO
Os materiais cimentícios de alto desempenho podem ser produzidos com a utilização de sílica ativa (SA) e de nanossílica (NS). Devido ao pequeno tamanho de suas partículas, esses materiais tendem a se aglomerar, diminuindo os seus potenciais reativos. Alguns pesquisadores estudaram métodos para dispersar essas partículas como ultrasonicadores e misturadores rotacionais, porém ainda é necessário realizar estudos sobre esses materiais, principalmente sobre o efeito da ultrasonicação da nanossílica coloidal. Dessa forma, esse estudo teve como objetivo avaliar o efeito da ultrasonicação (uso de ultrassom de alta energia) da sílica ativa e da nanossílica coloidal em pastas de cimento. Foram estudadas cinco pastas, sendo uma referência com $100 \%$ de cimento Portland CP V-ARI e as outras quatro substituindo $2 \%$ e $10 \%$ do cimento Portland por nanossílica coloidal e por sílica ativa, respectivamente, em seu estado natural e após a ultrasonicação. Foram realizados os ensaios de resistência à compressão, análise termogravimétrica (ATG), espectroscopia no infravermelho e porosimetria por intrusão de mercúrio (PIM) nas pastas. Os resultados mostraram que a utilização da NS coloidal em substituição ao cimento Portland aumentou a produção de C-S-H, o refinamento dos poros e a resistência à compressão das pastas, porém a utilização da SA em seu estado natural aumentou o tamanho dos poros e diminuiu o desempenho mecânico das pastas devido à aglomeração de suas partículas. Ao ultrasonicar a SA, houve maior produção de $\mathrm{C}-\mathrm{S}-\mathrm{H}$, refinamento dos poros e maior resistência à compressão quando comparada com a pasta com SA sem o processo de ultrasonicação, comprovando a efetividade desse método para a dispersão dessas partículas. Apesar disso, a ultrasonicação da NS coloidal não resultou em diferenças significativas na microestrutura e de desempenho mecânico das pastas.
\end{abstract}

Palavras-chave: Dispersão; resistência à compressão; análise termogravimétrica (ATG); porosimetria (PIM).

\section{ABSTRACT}

The high performance cementitious materials can be produced using silica fume (SF) and nanosilica (NS). Due to the small size of their particles, these materials became agglomerate, reducing their reactivity potentials. Some researchers have studied methods of dispersing these particles as ultrasonicators and rotational mixers, but studies on these materials are still needed, especially on the effect of colloidal nanosilica ultrasonication. Thus, this article aimed to evaluate the effect of ultrasonication (use of high energy ultrasound) of silica fume and colloidal nanosilica on cement pastes. Five pastes were investigated, a reference with $100 \%$ Portland cement CP V-ARI, and other four replacing $2 \%$ and $10 \%$ of the Portland cement by colloidal nanosilica and silica fume, respectively, in their natural state and after ultrasonication. The tests of compressive strength, thermogravimetry analysis (TGA), infrared spectroscopy and mercury intrusion porosimetry (MIP) were performed on pastes. The results showed that the use of colloidal NS in substitution of Portland cement increased C-S-H production, pore refinement and compressive strength of the pastes, however the use of SF in its natural state increased the pore size and decreased the mechanical performance of the pastes due to the agglomeration of its particles. By ultrasonication of SF, there was higher C-S-H production, pore refinement 
and compressive strength when compared to SF paste without the ultrasonication process, proving the effectiveness of this method for the dispersion of these particles. Nevertheless, ultrasonication of colloidal nanosilica did not result in significant differences in the microstructure and mechanical performance of the pastes.

Keywords: Dispersion; compressive strength; thermogravimetric analysis (TGA); porosimetry (MIP).

\section{INTRODUÇÃO}

As principais propriedades dos materiais cimentícios de alto desempenho ( $f_{c k}>50 \mathrm{MPa}$ ) no estado endurecido são elevada resistência mecânica e elevada durabilidade. Essas propriedades geralmente são alcançadas com a produção de materiais cimentícios com baixa relação água/aglomerante (a/agl) e com a utilização de materiais cimentícios suplementares (MCSs) altamente reativos e nanomateriais [1-7].

Um dos MCSs mais pesquisados atualmente para essa finalidade é a sílica ativa (SA), que pode ser encontrada comercialmente na forma não densificada ou densificada, com densidade aparente no estado solto entre 150 e $350 \mathrm{Kg} / \mathrm{m}^{3}$ e entre 350 e $700 \mathrm{Kg} / \mathrm{m}^{3}$, respectivamente [8]. Este material pozolânico é muito reativo devido às suas características como alto teor de $\mathrm{SiO}_{2}$ (superior à $90 \%$ ), seu elevado grau de amorfismo e a sua granulometria muito fina. A SA age de duas maneiras na microestrutura dos materiais cimentícios: o efeito pozolânico (químico) no qual a SA reage com o $\mathrm{CH}$ liberado durante a hidratação do cimento, formando C-S-H adicional que preenche os vazios capilares e o efeito fíller (físico) que densifica a microestrutura, pois as suas pequenas partículas preenchem os espaços entre os grãos de cimento Portland, diminuindo a porosidade dos materiais cimentícios [9].

Outro material bastante estudado é a nanossílica (NS), que pode ser utilizada em misturas binárias ou ternárias de cimento Portland. Ela é comercializada de duas formas: em pó ou em suspensão aquosa (nanossílica coloidal). Apesar de possuir as mesmas propriedades químicas que a SA, ela possui maior reatividade devido ao menor tamanho das suas partículas quando comparadas com o cimento Portland e com a SA. Quando totalmente dispersa, a NS apresenta um diâmetro equivalente médio de partículas menor que 0,01 $\mu \mathrm{m}$, enquanto da SA varia entre $0,1 \mu \mathrm{m}$ e $1,0 \mu \mathrm{m}$ e do cimento Portland varia entre $1 \mu \mathrm{m}$ e $100 \mu \mathrm{m}$ [2].

Ao utilizar a NS em conjunto com o cimento Portland, há uma maior densificação da matriz em comparação com a utilização da SA em conjunto com o cimento Portland [10]. Isso acontece devido à aceleração das reações de hidratação e à formação de mais C-S-H dos materiais cimentícios contendo NS nas primeiras idades [11]. Dessa forma, observa-se que tanto a SA como a NS contribuem para a melhoria do desempenho de pastas, argamassas e concretos [12-15].

Devido à SA e à NS serem materiais extremamente finos, eles tendem a se aglomerar. A aglomeração dessas partículas diminui a eficácia da SA e da NS quando utilizadas com o cimento Portland [1, 16]. Dessa forma, quanto mais dispersos esses materiais, maior é o desempenho mecânico dos materiais cimentícios. A alternativa encontrada comercialmente para evitar a aglomeração da NS é através de uma solução aquosa com dispersantes (NS coloidal). O sistema coloidal deve ser capaz de evitar a sedimentação e a aglomeração das partículas de NS devido às forças de Van der Waals. Dessa forma, a estabilidade do sistema coloidal é obtida pela força de repulsão entre as partículas. Apesar disso, RÊGO et al. [5] e BOLHASSANI e SAMANI [17] observaram através do microscópio eletrônico de transmissão (MET) partículas de NS coloidal aglomeradas. Dessa forma, observa-se que o sistema coloidal consegue manter as partículas de NS parcialmente dispersas, mas não garante a dispersão total das partículas de NS. Outros métodos utilizados para dispersão da SA e da NS são misturadores rotacionais e ultrasonicadores, sendo a ultrasonicação mais eficiente na dispersão dessas partículas [3, 18-21].

Apesar do crescente número de pesquisas que utilizaram esses métodos para dispersar a SA [18-19, 22-25] e a NS [26-32], não foram encontrados estudos que avaliaram o efeito da ultrasonicação da NS coloidal na microestrutura de materiais cimentícios. Isso representa uma lacuna importante para a comunidade científica atualmente, tendo em vista que o sistema coloidal pode não garantir a total dispersão das partículas de NS e o tamanho das partículas de NS influencia diretamente nas propriedades dos materiais cimentícios [5, 17].

Dessa forma, esse artigo tem como objetivo avaliar o efeito da ultrasonicação da sílica ativa e da nanossílica coloidal utilizadas em substituição parcial ao cimento Portland na microestrutura de pastas de cimento Portland, visando compreender a atuação destes componentes no desenvolvimento da hidratação do cimento Portland, na porosidade e nas propriedades mecânicas dos materiais cimentícios. 


\section{MATERIAIS E MÉTODOS}

\subsection{Materiais}

Para a realização desse estudo foi utilizado cimento Portland CP V-ARI, sílica ativa densificada (SA), nanossílica coloidal (NS) e aditivo superplastificante (SP) à base de policarboxilato. Esses materiais foram caracterizados em laboratório, conforme resultados mostrados na tabela 1.

Tabela 1: Caracterização do cimento Portland, da sílica ativa, da nanossílica coloidal e do aditivo superplastificante.

\begin{tabular}{|c|c|c|c|c|}
\hline Material & Propriedade & & Resultado & Limites \\
\hline \multirow{8}{*}{$\begin{array}{l}\text { Cimento } \\
\text { Portland }\end{array}$} & \multicolumn{2}{|c|}{$\begin{array}{l}\text { Teor de água da pasta de } \\
\text { consistência normal }(\%)\end{array}$} & 35,50 & - \\
\hline & \multirow{2}{*}{ Tempo de pega (min) } & Início & 120 & $\geq 60 \min (\mathrm{ABNT} N \mathrm{NBR} 16697: 2018)[33]$ \\
\hline & & Fim & 175 & $\leq 600 \min (\mathrm{ABNT} N \mathrm{NBR} 16697: 2018)[33]$ \\
\hline & \multicolumn{2}{|c|}{ Índice de finura na peneira $75 \mu \mathrm{m}(\%)$} & 0,90 & $\leq 6,0 \%($ ABNT NBR 16697:2018) [33] \\
\hline & \multicolumn{2}{|c|}{ Massa específica $\left(\mathrm{g} / \mathrm{cm}^{3}\right)$} & 3,00 & - \\
\hline & \multirow{3}{*}{$\begin{array}{c}\text { Resistência à compressão } \\
(\mathrm{MPa})\end{array}$} & $1 \mathrm{dia}$ & 25,4 & $\geq 14 \mathrm{MPa}(\mathrm{ABNT}$ NBR 16697:2018) [33] \\
\hline & & 3 dias & 36,1 & $\geq 24 \mathrm{MPa}(\mathrm{ABNT}$ NBR 16697:2018) [33] \\
\hline & & 7 dias & 42,7 & $\geq 34 \mathrm{MPa}(\mathrm{ABNT}$ NBR $16697: 2018)[33]$ \\
\hline \multirow{3}{*}{ SA } & \multicolumn{2}{|c|}{ Massa específica $\left(\mathrm{g} / \mathrm{cm}^{3}\right)$} & 2,16 & - \\
\hline & \multicolumn{2}{|c|}{$\begin{array}{l}\text { Densidade aparente no estado solto } \\
\left(\mathrm{kg} / \mathrm{m}^{3}\right)\end{array}$} & 595,07 & - \\
\hline & \multicolumn{2}{|c|}{ Finura na peneira $45 \mu \mathrm{m}(\%)$} & 9,10 & $10,0 \%$ (ABNT NBR 13956-1:2012) [34] \\
\hline \multirow{4}{*}{ NS } & \multicolumn{2}{|c|}{ Massa específica $\left(\mathrm{g} / \mathrm{cm}^{3}\right)$} & 1,20 & - \\
\hline & \multicolumn{2}{|l|}{$\mathrm{pH}$} & 10,5 & - \\
\hline & \multicolumn{2}{|l|}{ Teor de sólidos (\%) } & 30 & - \\
\hline & \multicolumn{2}{|c|}{ Diâmetro médio (nm) } & 22,75 & - \\
\hline \multirow{4}{*}{ SP } & \multicolumn{2}{|l|}{ Cor } & $\begin{array}{l}\text { Líquido } \\
\text { alaranjado }\end{array}$ & $\begin{array}{c}\text { Deve ser igual ao informado pelo } \\
\text { fabricante (ABNT NBR 11768:2011) [35] }\end{array}$ \\
\hline & \multicolumn{2}{|c|}{ Massa específica $\left(\mathrm{g} / \mathrm{cm}^{3}\right)$} & 1,095 & $1,11 \pm 0,02 \mathrm{~g} / \mathrm{cm}^{3}($ ABNT NBR 11768:2011) [35] \\
\hline & \multicolumn{2}{|l|}{ Teor de sólidos (\%) } & 40 & - \\
\hline & \multicolumn{2}{|l|}{$\mathrm{pH}$} & 3,8 & - \\
\hline
\end{tabular}

A composição química realizada através do ensaio de fluorescência de raios-X do CP V-ARI, da SA e da NS é apresentada na tabela 2. Para a realização do ensaio de perda ao fogo, a NS coloidal foi previamente seca à temperatura ambiente por 72 horas.

Tabela 2: Composição química do cimento Portland, da sílica ativa e da nanossílica.

\begin{tabular}{c|c|c|c|c|c|c|c|c|c|c|c}
\hline \multirow{2}{*}{-} & \multicolumn{10}{c}{ Composição química (\%) } \\
\cline { 2 - 14 } & $\mathbf{S i O}_{\mathbf{2}}$ & $\mathbf{A l}_{\mathbf{2}} \mathbf{O}_{\mathbf{3}}$ & $\mathbf{M g O}$ & $\mathbf{F e}_{\mathbf{2}} \mathbf{O}_{\mathbf{3}}$ & $\mathbf{C a O}$ & $\mathbf{N a}_{\mathbf{2}} \mathbf{O}$ & $\mathbf{K}_{\mathbf{2}} \mathbf{O}$ & $\mathbf{T i O}_{\mathbf{2}}$ & $\mathbf{P}_{\mathbf{2}} \mathbf{O}_{\mathbf{5}}$ & $\mathbf{M n O}$ & $\mathbf{P F}^{*}$ \\
\hline $\mathbf{C P}$ V-ARI & 19,91 & 4,20 & 1,78 & 2,20 & 63,61 & 0,38 & 0,36 & 0,23 & 0,17 & 0,07 & 3,36 \\
\hline SA & 94,33 & $<0,01$ & 0,49 & 0,19 & 0,78 & 0,39 & 1,04 & 0,02 & 0,14 & 0,06 & 2,28 \\
\hline NS & 90,61 & $<0,01$ & 0,10 & 0,11 & 0,02 & 2,03 & 0,03 & 0,03 & $<0,01$ & $<0,01$ & 6,19 \\
\hline
\end{tabular}

* PF: Perda ao fogo.

Os principais componentes químicos do cimento foram óxido de cálcio $(\mathrm{CaO})$ com o teor de 63,61\% e dióxido de silício $\left(\mathrm{SiO}_{2}\right)$ com $19,91 \%$ devido às suas matérias-primas principais (calcário e argila), ao contrário da $\mathrm{SA}$ e da NS que resultaram em teores de $\mathrm{SiO}_{2}$ superiores a $90 \%$ devido à sua origem. O cimento Portland atendeu aos requisitos químicos da ABNT NBR 16697:2018 [33], com teores de óxido de magnésio e de perda ao fogo inferiores a 6,5\%. A sílica ativa atendeu aos requisitos químicos da ABNT NBR 13956- 
1:2012 [34], cujo teor de $\mathrm{SiO}_{2}$ deve ser maior ou igual a 85,0\% e a perda ao fogo deve ser no máximo 6,0\%. Apesar das composições químicas da SA e da NS serem semelhantes, o teor de perda ao fogo da NS foi maior devido à possibilidade de não evaporação da quantidade total de água durante as 72 horas de secagem ao ar livre antes da realização do ensaio de perda ao fogo. Para caracterizar a SA e a NS, também foi realizado o ensaio de difração de raios-X, no qual foi constatado elevado grau de amorfismo dos dois materiais, como pode ser observado na figura 1 .

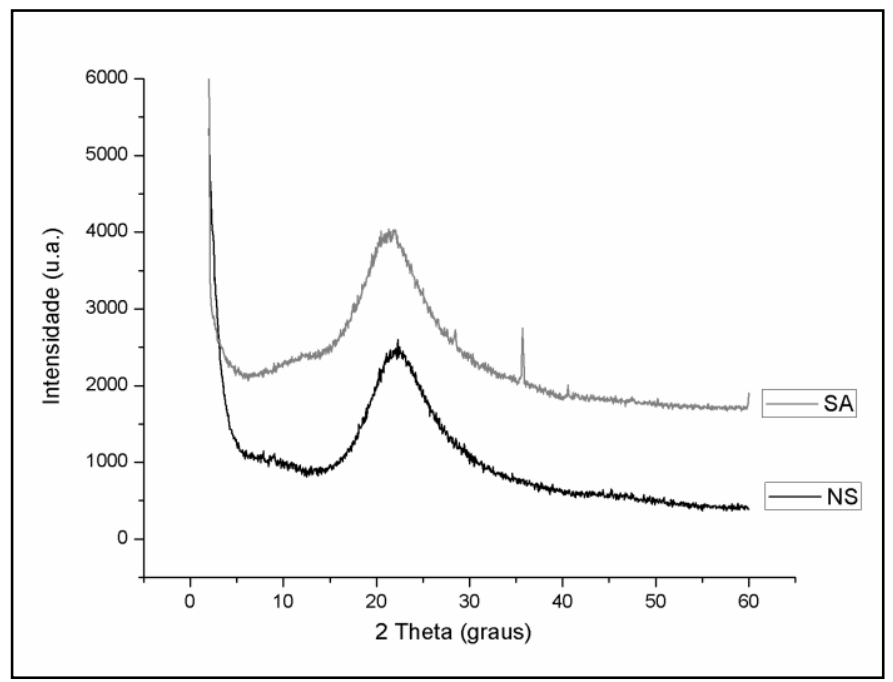

Figura 1: Difratograma de raios-X da SA e da NS.

Para a SA, foram realizadas imagens no microscópio eletrônico de varredura (MEV) e foi verificada a distribuição granulométrica através do ensaio de granulometria a laser. As imagens de MEV auxiliaram na análise da morfologia e do tamanho das partículas da SA. A amostra foi fixada com fita adesiva de carbono sobre um porta amostras e foi metalizada com carbono como material condutor. O equipamento utilizado nesse ensaio foi o microscópio eletrônico de varredura modelo JEOL QUANTA 450 operado em vácuo, com tensão de aceleração de elétrons (HV) de $15 \mathrm{kV}$ e distância de trabalho (WD) de 15,2 mm.

O equipamento utilizado para o ensaio de granulometria a laser foi o Cilas Particle Size 1180, que fornece uma faixa de medição de tamanho de partículas entre $0,04 \mu \mathrm{m}$ e $2.500 \mu \mathrm{m}$. O objetivo desse ensaio foi verificar o tamanho das partículas de SA. Para isso, a SA foi misturada com água e colocada sob o efeito de pulsos ultrassônicos por 60 segundos. A partir dessa solução, foi gerada uma curva de distribuição granulométrica, na qual foram definidos o diâmetro médio, $\mathrm{D}_{10}, \mathrm{D}_{50}$ e $\mathrm{D}_{90}$. Esses valores significam os diâmetros das partículas quando a curva granulométrica apresentou porcentagem acumulada de $10 \%, 50 \%$ e $90 \%$ do total de partículas, respectivamente.

Para avaliar o tamanho das partículas da NS coloidal, foi realizado o Dynamic Light Scattering (DLS), que significa espalhamento dinâmico de luz. Esse ensaio foi realizado no equipamento Zetasizer Nano ZS90 da Malvern. Para a realização do DLS, foi utilizado índice de refração igual a 1,458 e a absorção igual a 0,01, referentes aos grupos silicatos. Primeiramente tentou-se realizar o ensaio com a NS coloidal em seu estado natural, porém o equipamento identificou alto grau de partículas sólidas. Dessa forma, foi necessário realizar a diluição da NS coloidal em água deionizada. Para obter maior confiabilidade nos resultados foram realizadas três diferentes diluições nos teores de $2 \%, 4 \%$ e $8 \%$ da NS coloidal em água deionizada, nas quais foram obtidos resultados semelhantes e optou-se por apresentar os resultados com a diluição de $4 \%$ da NS em água deionizada.

\subsection{Produção das pastas}

Para realizar o processo de ultrasonicação, a SA e a NS foram colocadas em um béquer de vidro junto com o aditivo superplastificante e com $50 \%$ da água de mistura de cada traço. O equipamento utilizado foi um ultrasonicador VCX 750 da Sonics com sonda ultrassônica modelo CV334. Foi utilizada amplitude de 75\% e tempo efetivo de ultrasonicação de 10 minutos em ciclos de 50 segundos com de aplicação de pulsos ultrassônicos e 10 segundos sem aplicação de pulsos, parâmetros adaptados de BARKOULA et al. [29]. Em volta do béquer com a mistura a ser ultrasonicada foi utilizado gelo para evitar a evaporação de água.

Foram preparados cinco traços de pastas, substituindo parcialmente o cimento Portland pela nanossíli- 
ca coloidal ou pela sílica ativa, todas com relação a/agl=0,40. O teor de aditivo superplastificante foi variado até a pasta apresentar espalhamento igual a 140 $\pm 10 \mathrm{~mm}$ no ensaio de mini slump descrito por KANTRO [36]. Para manter a relação a/agl exata, foi descontada a quantidade de água da nanossílica coloidal (70\% de sua massa) e a quantidade de água do aditivo superplastificante (60\% de sua massa).

Foi verificado o efeito da substituição de $2 \%$ do cimento Portland pela nanossílica coloidal, teor utilizado em diversas pesquisas [4, 26, 37-39] e de 10\% do cimento Portland pela sílica ativa (teor de substituição recomendado pela ABNT NBR 13956-1:2012 [34] e muito utilizado em pesquisas [38-41]. Além disso, foi estudado o efeito da ultrasonicação desses dois materiais nas pastas de cimento. Foram realizados os seguintes ensaios nas pastas: resistência à compressão, análise termogravimétrica (ATG), espectroscopia no infravermelho e porosimetria por intrusão de mercúrio (PIM). Na tabela 3 é mostrada a nomenclatura, a composição e o traço unitário das pastas.

Tabela 3: Nomenclatura, composição e traço unitário das pastas.

\begin{tabular}{|c|c|c|c|c|c|c|}
\hline \multirow[b]{2}{*}{ Nomenclatura } & \multirow[b]{2}{*}{ Composição } & \multicolumn{5}{|c|}{ Traço unitário } \\
\hline & & $\begin{array}{c}\text { CP V- } \\
\text { ARI (g) }\end{array}$ & $\begin{array}{l}\text { SA } \\
\text { (g) }\end{array}$ & $\begin{array}{l}\text { NS coloidal (sus- } \\
\text { pensão aquosa } 30 \% \\
\text { de NS) (g) }\end{array}$ & $\begin{array}{l}\text { SP } \\
(g)\end{array}$ & $\begin{array}{c}\text { Água } \\
\text { (g) }\end{array}$ \\
\hline REF & $100 \%$ CP V-ARI & 1,0000 & 0,0000 & 0,0000 & 0,0050 & 0,3970 \\
\hline $2 \mathrm{NS}$ & $98 \%$ CP V-ARI + $2 \%$ NS (NUS) & 1,0000 & 0,0000 & 0,0680 & 0,0112 & 0,3538 \\
\hline $2 \mathrm{NSU}$ & $98 \%$ CP V-ARI + 2\% NS (US) & 1,0000 & 0,0000 & 0,0680 & 0,0122 & 0,3532 \\
\hline 10SA & $90 \%$ CP V-ARI + $10 \%$ SA (NUS) & 1,0000 & 0,1111 & 0,0000 & 0,0067 & 0,4405 \\
\hline 10SAU & $90 \%$ CP V-ARI + $10 \%$ SA (US) & 1,0000 & 0,1111 & 0,0000 & 0,0078 & 0,4398 \\
\hline
\end{tabular}

NUS: Não ultrasonicada.

US: Ultrasonicada.

A preparação das pastas seguiu as recomendações na ABNT NBR 16606:2017 [42], com adaptações. Primeiro foram adicionados todos os materiais na fase líquida (água e aditivo superplastificante, além de nanossílica coloidal no estado natural, nanossílica coloidal ultrasonicada ou sílica ativa ultrasonicada) em uma cuba de aço inox e depois foi adicionado o cimento Portland. Após o contato do cimento com a mistura, foram contabilizados 30 segundos em repouso. Depois foi realizada a mistura com o auxílio do misturador planetário durante 30 segundos na velocidade lenta. O misturador foi desligado por 60 segundos, sendo realizada a raspagem das paredes internas da cuba durante os primeiros 30 segundos. Por fim, o misturador planetário foi ligado na velocidade alta por 60 segundos.

Com essas pastas, foram moldados quatorze corpos de prova de $50 \mathrm{~mm}$ de diâmetro e $100 \mathrm{~mm}$ de altura para cada traço. Após a moldagem, os corpos de prova foram colocados em câmara úmida por 24 horas e depois em cura submersa em água saturada com cal até a idade de ensaio.

\subsection{Técnicas de avaliação das pastas}

Foram retificados e rompidos 3 corpos de prova de cada traço aos 1, 3, 7 e 28 dias de hidratação para verificação da resistência à compressão com tolerância de tempo para ruptura igual ao estabelecido pela ABNT NBR 7215:1996 [43]. Para esse ensaio, foi utilizada uma máquina universal para ensaios mecânicos da marca Denison, com capacidade máxima de carga de 200 toneladas. Após o rompimento dos corpos de prova, foi feita a paralisação da hidratação das pastas com os fragmentos da parte interna dos corpos de prova utilizados no ensaio de resistência à compressão utilizando uma das metodologias de SCRIVENER et al. [44] com adaptações. $\mathrm{O}$ procedimento consistiu na imersão dos fragmentos em isopropanol por 6 horas e secagem em estufa à $40 \pm 1^{\circ} \mathrm{C}$ por 24 horas. As amostras foram armazenadas em um recipiente contendo sílica gel para evitar a hidratação e cal sodada para evitar a carbonatação até o dia de realização dos ensaios microestruturais. Esses fragmentos das pastas foram utilizados posteriormente para os ensaios de análise termogravimétrica (ATG) e infravermelho. O processo de paralisação da hidratação das pastas é mostrado na figura 2. 


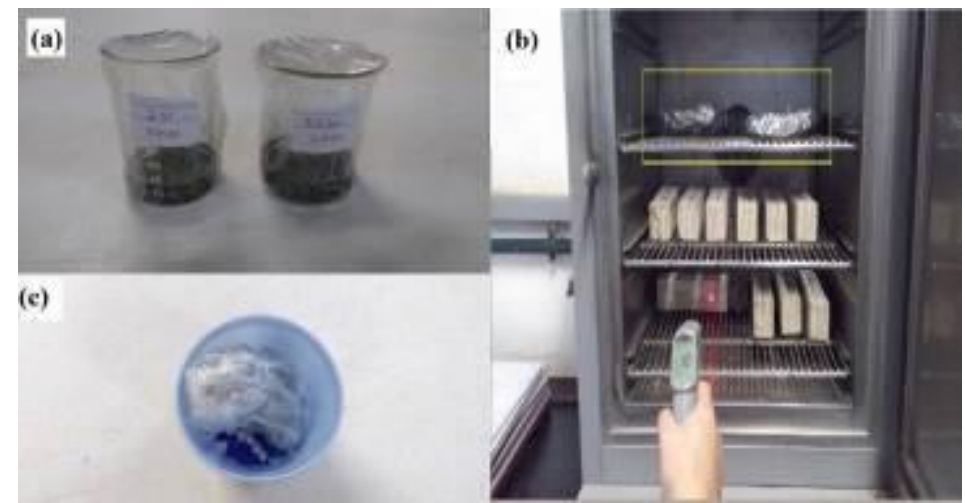

Figura 2: Etapas da paralisação da hidratação das pastas (a) imersão em isopropanol por 6 horas; (b) secagem em estufa à $40 \pm 1^{\circ} \mathrm{C}$ por 24 horas; (c) armazenamento com sílica gel e cal sodada.

Os outros dois corpos de prova serviram para realizar o ensaio de porosimetria por intrusão de mercúrio (PIM). A preparação das amostras consistiu em cortar um cubo com aproximadamente $1 \mathrm{~cm}$ de aresta com o auxílio de uma serra circular utilizando a parte interna dos corpos de prova. $\mathrm{O}$ processo de paralisação da hidratação dessas amostras foi similar ao utilizado para os demais ensaios microestruturais, porém o tempo em isopropanol foi de 24 horas devido ao maior tamanho da amostra. Para os ensaios de análise termogravimétrica (ATG) e infravermelho, as pastas foram moídas com um almofariz, já para o ensaio de PIM foi utilizada a amostra da mesma forma como foi realizada a paralisação da hidratação.

Com os resultados de resistência à compressão das pastas aos 28 dias de hidratação, foi realizada uma análise de variância ANOVA para observar se a substituição do cimento Portland pela SA ou pela NS e o processo de ultrasonicação foram significativos para alterar a resistência à compressão das pastas nessa idade, considerando nível de significância 0,05 . Depois foi realizada uma análise através do teste de Duncan no software Statistica, versão 10, com intervalo de confiança de $95 \%$. Nesse teste, o desempenho mecânico de cada pasta foi classificado em grupos de resistência que levaram em consideração a resistência média à compressão e o desvio padrão das amostras ensaiadas.

A perda de massa em função da faixa de temperatura referente ao C-S-H e ao $\mathrm{CH}$ das pastas aos 1, 3, 7 e 28 dias foi avaliada através da análise termogravimétrica (ATG). O equipamento utilizado foi o analisador térmico simultâneo SDT Q600 da TA Instruments, que possui forno cilíndrico horizontal com conversor digital acoplado a um computador. Em um cadinho de alumínio, foram utilizadas 10,5 $\pm 0,5 \mathrm{mg}$ de cada amostra previamente moída. A temperatura inicial de análise foi $30 \pm 5^{\circ} \mathrm{C}$ até a temperatura de $1000^{\circ} \mathrm{C}$, com taxa de aquecimento de $10^{\circ} \mathrm{C} / \mathrm{min}$ e aquecimento sob atmosfera de $\mathrm{N}_{2}$ com fluxo de $50 \mathrm{ml} / \mathrm{min}$.

A espectroscopia no infravermelho foi utilizada para identificar as fases das pastas aos 28 dias de hidratação por meio das bandas de absorção observadas na região com comprimento de onda entre $4000 \mathrm{~cm}^{-1} \mathrm{e}$ $400 \mathrm{~cm}^{-1}$. As pastas previamente moídas foram misturadas com brometo de potássio $(\mathrm{KBr})$ na proporção de 1:100 para preparar as pastilhas com o auxílio de uma prensa. Esse ensaio foi realizado no equipamento modelo PerkinElmer FT-IR Spectrometer, Frontier, conectado a um computador cujos dados foram gerados pelo software WinFIRST-FTIR. Foram realizadas três análises para cada pasta, nas quais foi realizado o background com ar, sendo utilizada a média entre esses ensaios como resultado nesse artigo.

Para avaliar a distribuição do tamanho dos poros nas pastas aos 28 dias de hidratação, foi realizado o ensaio de porosimetria por intrusão de mercúrio (PIM). A PIM consiste na aplicação de uma pressão para forçar a intrusão do mercúrio nos poros do material. A pressão necessária é inversamente proporcional ao diâmetro dos poros, conforme a equação de Washburn (equação 1) [45]. O equipamento utilizado foi o Micromeritics Poresizer, modelo 9320. Foi utilizado um ângulo de contato de $130^{\circ} \mathrm{C}$, mercúrio com tensão superficial de $0,485 \mathrm{~N} / \mathrm{m}$ e densidade de $13,5335 \mathrm{~g} / \mathrm{mL}$.

$\mathrm{p}=(-4 \cdot \gamma \cdot \cos \theta) / \mathrm{d}$

Onde:

$\mathrm{p}=$ pressão externa aplicada;

$\gamma=$ tensão superficial do mercúrio; 
$\theta=$ ângulo de contato entre o mercúrio e o sólido capilar; $\mathrm{d}=$ diâmetro do poro capilar.

\section{RESULTADOS E DISCUSSÕES}

\subsection{Morfologia da SA e da NS}

Através das micrografias mostradas na figura 3, observa-se grãos de SA com diferentes tamanhos. Ao aproximar a imagem, foi observado que pequenos grãos se aglomeraram para formar um grão maior. Isso demonstra que a SA utilizada em seu estado natural não tem seu potencial totalmente aproveitado, sendo necessário algum método para dispersar esses aglomerados e aumentar o seu potencial reativo.

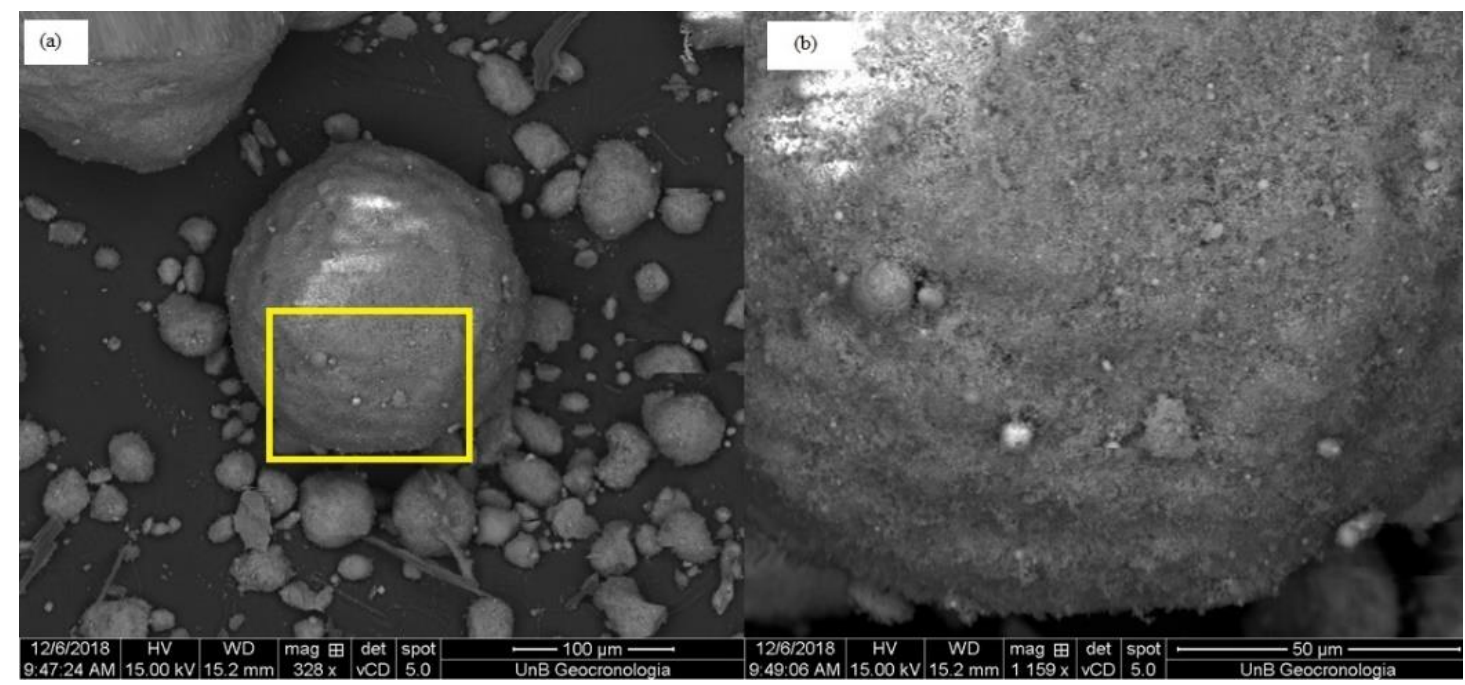

Figura 3: Micrografia de MEV da sílica ativa em seu estado natural com aproximação de (a) 328x; (b) 1159x.

Isso foi comprovado também através da realização do ensaio de granulometria a laser, como mostrado na figura 4. Mesmo após 60 segundos de aplicação de pulsos ultrassônicos antes de realizar o ensaio de granulometria a laser, o $\mathrm{D}_{10}$ foi igual a $5,19 \mu \mathrm{m}$, o $\mathrm{D}_{50}$ igual a $31,37 \mu \mathrm{m}$, o $\mathrm{D}_{90}$ igual a $58,75 \mu \mathrm{m}$ e o diâmetro médio igual a $31,55 \mu \mathrm{m}$. Dessa forma, observa-se que a SA utilizada nessa pesquisa possui diâmetro de partícula superior ao abordado na literatura como totalmente dispersa, entre $0,1 \mu \mathrm{m}$ e $1,0 \mu \mathrm{m}$ [4], comprovando a aglomeração das suas partículas.

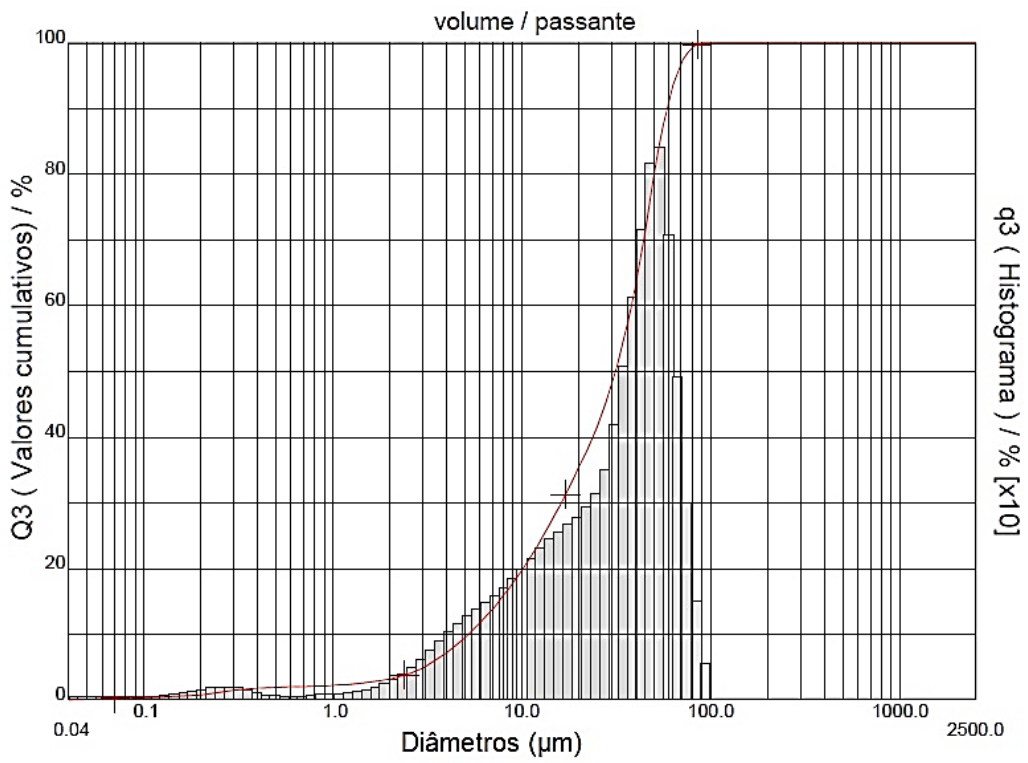

Figura 4: Distribuição granulométrica da SA através do ensaio de granulometria a laser. 
Na figura 5 é mostrada a distribuição do tamanho das partículas de NS coloidal obtidas no ensaio de DLS. A nanossílica coloidal apresentou diâmetro médio de partículas de 22,75 nm, com distribuição de tamanho de partículas entre 7,5 $\mathrm{nm}$ e $91,3 \mathrm{~nm}$.

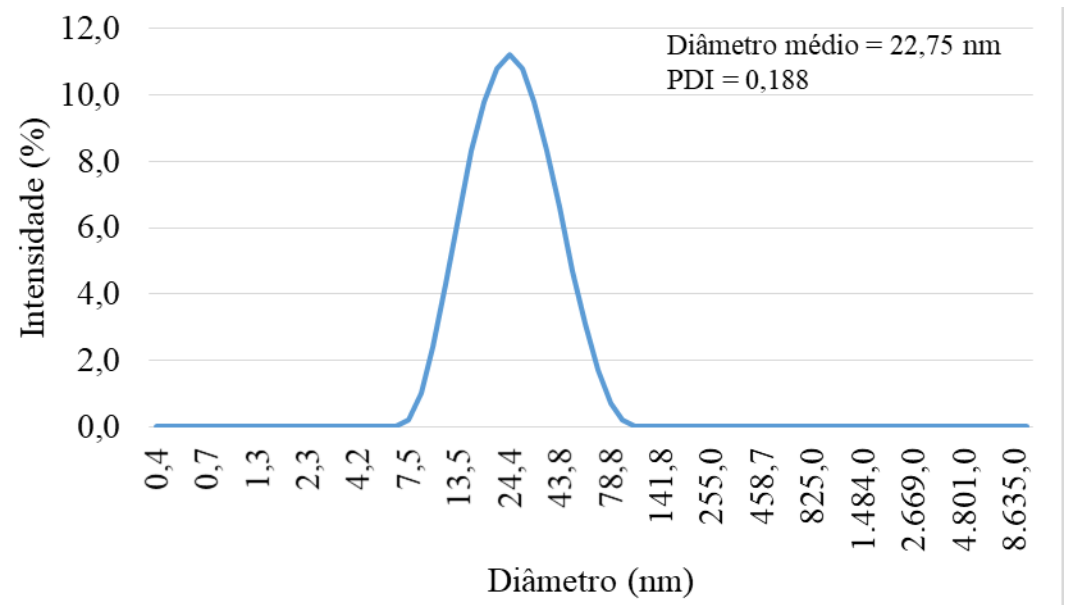

Figura 5: Distribuição do tamanho das partículas de NS coloidal através do ensaio de DLS.

Apesar de aparentemente o sistema coloidal manter as partículas de NS dispersas, pois apresentam diâmetro médio igual a $22,75 \mathrm{~nm}$, as partículas não encontram-se totalmente dispersas. Isso foi comprovado no estudo realizado por RÊGO et al. [5], que utilizaram a mesma NS coloidal do presente estudo. Os autores observaram através do microscópio eletrônico de transmissão (MET) que as partículas de NS encontravam-se parcialmente aglomeradas.

\subsection{Teor de aditivo superplastificante}

Os resultados do teor de aditivo superplastificante necessário para obter o espalhamento de $140 \pm 10 \mathrm{~mm}$ no ensaio de mini slump são mostrados na figura 6 .

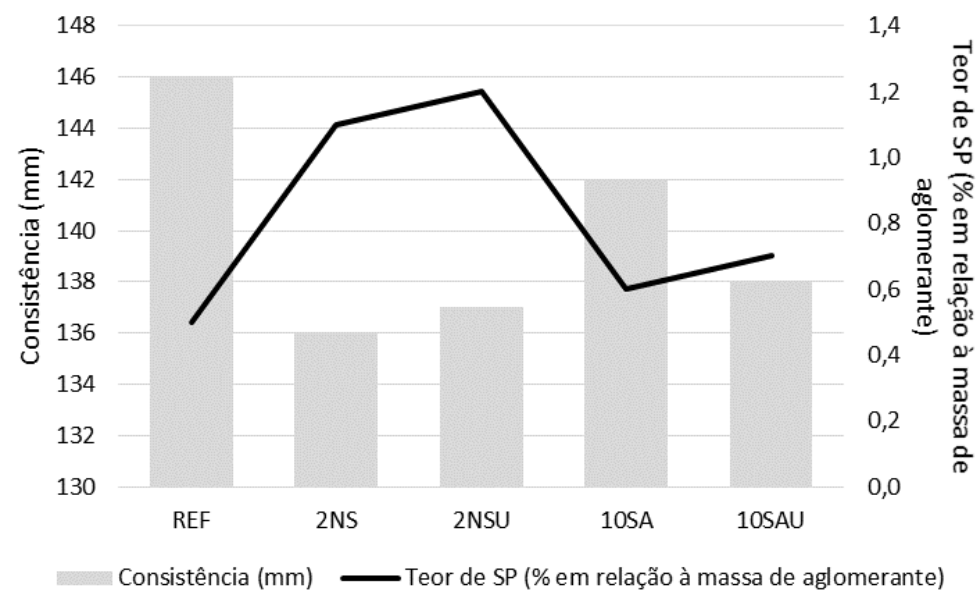

Figura 6: Teor de aditivo superplastificante necessário para obter o espalhamento de $140 \pm 10 \mathrm{~mm}$ no ensaio de mini slump.

Ao substituir o cimento Portland pela SA ou pela NS coloidal, as pastas se tornaram mais consistentes em comparação com a pasta REF, sendo necessário aumentar o teor de aditivo superplastificante para alcançarem consistências semelhantes. Com apenas $2 \%$ de NS foi necessário mais aditivo superplastificante $(1,10 \%)$ do que $10 \%$ de SA $(0,60 \%)$. SENFF et al. [46] verificaram essa mesma tendência através de parâmetros reológicos de pastas de cimento com teores de $0 \%$ a $10 \%$ de SA, $1 \%$ de NS e $0 \%$ a $0,5 \%$ de SP. 
BOLHASSANI e SAMANI [17], CHEN et al. [37] e ANDRADE et al. [6] também observaram o aumento da consistência das pastas com a incorporação de NS em relação às pastas com SA que por sua vez demandaram mais SP que a pasta referência para manter a mesma consistência. Esse comportamento foi justificado pelo aumento da adsorção de água da mistura fresca com o aumento de partículas com maiores superfícies específicas.

Na pesquisa realizada por BOLHASSANI e SAMANI [17], foram comparadas nanossílicas com diferentes tamanhos. A NS com $5 \mathrm{~nm}$ de diâmetro necessitou de maior teor de aditivo superplastificante que a NS com $25 \mathrm{~nm}$ de diâmetro devido à sua maior superfície específica. Na presente pesquisa, ao ultrasonicar a NS não houve diferença significativa na consistência da pasta 2 NSU em relação à pasta 2 NS, indicando assim que não houve efeito significativo no tamanho das partículas de NS ao serem ultrasonicadas. Ao ultrasonicar a SA, houve aumento da demanda de SP, indicando que o processo de ultrasonicação foi eficiente para dispersar as partículas de SA.

\subsection{Resistência à compressão}

Os resultados de resistência à compressão das pastas aos 1, 3, 7 e 28 dias são mostrados na figura 7.

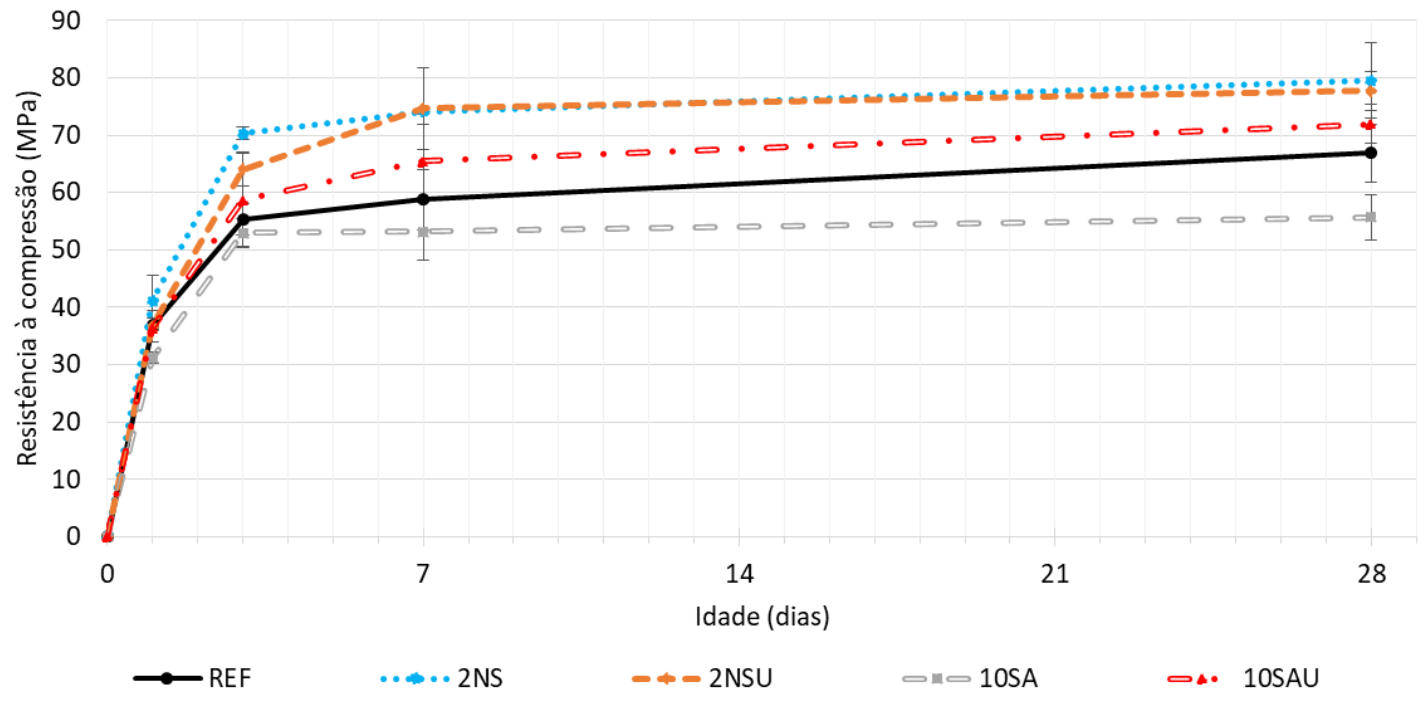

Figura 7: Resistência à compressão das pastas aos 1, 3, 7 e 28 dias de hidratação.

As pastas 2NS e 2NSU apresentaram resistências à compressão semelhantes entre si e maiores que as demais pastas. A pasta 2NS ganhou resistência principalmente até os 3 dias e depois tendeu a estabilizar, já a pasta 2NSU ganhou resistência principalmente até os 7 dias e depois também tendeu a estabilizar. A pasta 10SAU resultou em resistência à compressão intermediária, seguida pela pasta REF e por último pela pasta 10SA aos 28 dias.

$\mathrm{Na}$ análise de variância ANOVA foi constatado um p-valor menor que o nível de significância de 0,05. Dessa forma, houve diferença significativa na resistência à compressão entre as pastas aos 28 dias de hidratação. Portanto, para observar quais pastas resultaram em resistências homogêneas e heterogêneas, foi realizado do teste de Duncan, como mostrado na tabela 4.

Tabela 4: Teste de Duncan dos resultados de resistência à compressão das pastas aos 28 dias de hidratação.

\begin{tabular}{c|c|c|c|c|c|c}
\hline \multirow{4}{*}{ IDADE } & AMOSTRA & $\begin{array}{c}\text { RESISTÊNCIA MÉDIA À } \\
\text { COMPRESSÃO (MPa) }\end{array}$ & $\begin{array}{c}\text { DESVIO } \\
\text { PADRÃO } \\
\text { (MPa) }\end{array}$ & GRUPO 1 & GRUPO 2 & GRUPO 3 \\
\hline \multirow{5}{*}{28 DIAS } & REF & 66,8 & 5,1209 & & $X$ & \\
\cline { 2 - 7 } & $2 \mathrm{NS}$ & 79,5 & 6,6260 & & & $\mathrm{X}$ \\
\cline { 2 - 7 } & 2NSU & 77,7 & 3,3645 & & & $\mathrm{X}$ \\
\cline { 2 - 7 } & 10SA & 55,7 & 4,0079 & $\mathrm{X}$ & $\mathrm{X}$ & $\mathrm{X}$ \\
\hline
\end{tabular}


Devido ao grau de aglomeração da SA, a pasta 10SA resultou na menor resistência à compressão, pois a SA não teve o seu potencial reativo atingido aos 28 dias. Esse comportamento divergiu dos resultados de LI et al. [39], que observaram ganho de resistência de argamassas contendo $10 \%$ de SA aos 7 dias de hidratação com diferentes relação a/agl (entre 0,25 e 0,40). ANDRADE et al. [6] também observaram aumento na resistência à compressão de pastas com relação a/agl $=0,35$ contendo $10 \%$ de $\mathrm{SA}$ aos 7 dias de hidratação. RÊGO et al. [5] observaram aumento de $15 \%$ da resistência à compressão de pastas de cimento com relação a/agl= 0,35 substituindo $10 \%$ do cimento Portland por SA em comparação com a pasta referência aos 28 dias de hidratação. Essa melhoria no desempenho mecânico foi justificada pelos autores principalmente pela reação pozolânica da SA com o $\mathrm{CH}$.

O aumento no desempenho mecânico das pastas com NS desde as primeiras idades é atribuído ao efeito combinado da atividade pozolânica, do efeito dos pontos de nucleação e do efeito fíler [47-48]. Ao ultrasonicar a NS coloidal não houve diferença significativa no desempenho mecânico da pasta 2NSU (classificada no grupo 3) em relação à pasta 2NS (classificada no grupo 3), corroborando com os resultados mostrados na figura 6 que indicaram que não houve efeito da ultrasonicação no tamanho das partículas de NS coloidal. Ao ultrasonicar a SA houve aumento da resistência à compressão da pasta 10SAU (classificada nos grupos 2 e 3) em relação à pasta 10SA (classificada no grupo 1). Esse comportamento demonstra que o elevado grau de aglomeração da SA sem o processo de ultrasonicação além de deixar de contribuir no efeito fíler e de pontos de nucleação nas primeiras idades também não contribuiu com a atividade pozolânica aos 28 dias. Ao ultrasonicar a SA houve aumento na resistência à compressão da pasta 10SAU em relação à pasta 10SA aos 7 dias, mesma idade em que LI et al. [39] e ANDRADE et al. [6] observaram aumento da resistência ao incorporar a SA. Isso comprova que o grau de aglomeração da sílica influencia diretamente na sua reatividade pozolânica e que a ultrasonicação é eficaz para dispersar as partículas de SA.

\subsection{Análise termogravimétrica (ATG)}

Através do ensaio de termogravimetria, foi possível obter a variação da perda de massa em função do aumento da temperatura das pastas aos 1, 3, 7 e 28 dias de hidratação. Foram quantificadas as perdas de massa nas faixas de temperatura relacionadas com o C-S-H e com o $\mathrm{CH}\left(135-150^{\circ} \mathrm{C}\right.$ e $400-500^{\circ} \mathrm{C}$, respectivamente) indicadas por ZHANG et al. [40]. Com a perda de massa das pastas na faixa de temperatura referente ao $\mathrm{CH}$, utilizando-se de cálculos estequiométricos, foi possível relacionar a massa molar do hidróxido de cálcio (74 $\mathrm{g} / \mathrm{mol}$ ) com a massa molar da água $(18 \mathrm{~g} / \mathrm{mol})$ e determinar a quantidade do $\mathrm{CH}$ na referida temperatura. Ao multiplicar o percentual da perda de massa na faixa de temperatura do $\mathrm{CH}$ por 4,11 (relação entre as massas molares do $\mathrm{CH}$ e da água), foi possível obter o teor de $\mathrm{CH}$ em relação à massa total das pastas estudadas, como pode ser observado na equação 2.

Teor de $\mathrm{CH}=4,11 \times$ teor de água volatizada

Além disso, é possível obter os índices de $\mathrm{CH}$ e de C-S-H das pastas em relação à pasta REF dividindo o teor da pasta que se deseja calcular pelo teor da pasta REF e multiplicar o resultado por $100 \%$. Na tabela 5 são mostrados o índice de C-S-H das pastas em relação à pasta REF e o índice de CH das pastas em relação à pasta REF aos 1, 3, 7 e 28 dias de hidratação.

Em geral, foi possível observar que em todas as idades houve redução do índice de $\mathrm{CH}$ e aumento do índice de C-S-H das pastas com SA ou NS em comparação com a pasta REF devido à reação pozolânica e a menor quantidade de cimento das misturas com esses dois materiais pozolânicos. Apenas quatro resultados obtidos divergiram desse padrão (índice de $\mathrm{CH}$ das pastas 2NSU e 10SA com 1 dia de hidratação e índice de C-S-H da pasta 10SA aos 7 e 28 dias de hidratação), porém todos com diferença menor que 5\% em relação à pasta REF.

Observou-se uma grande influência da NS no aumento do consumo do CH para formação de mais CS-H devido à sua reatividade principalmente nas primeiras idades, assim como observado por HARUEHANSAPONG et al., [47] e KHALOO et al., [48]. Aos 1 e 3 dias, houve maior consumo de CH da pasta 2NS em comparação com a pasta 2NSU. Porém, a partir dos 7 dias não houve diferença significativa (maior que 5\%) nesse índice ao comparar essas pastas. Ao ultrasonicar a SA houve redução do teor de $\mathrm{CH}$ da pasta $10 \mathrm{SAU}$ em relação à pasta 10SA. Apesar disso, somente foi observado o aumento maior que $5 \%$ do índice de C-S-H da pasta 10SAU em relação à pasta 10SA a partir dos 7 dias de hidratação, idade na qual LI et al. [39] e ANDRADE et al. [6] indicaram início da reação pozolânica da SA.

RÊGO et al. [5] constataram redução do teor de $\mathrm{CH}$ ao substituir o cimento Portland por $10 \%$ de SA 
em comparação com a pasta referência aos 2 e 28 dias de hidratação. Os autores atribuíram essa redução a dois fatores: menor quantidade de cimento incorporado na mistura e reação pozolânica. Na presente pesquisa, chama-se atenção que mesmo as pastas com NS possuindo maior quantidade de cimento Portland que as pastas com $\mathrm{SA}$, os teores de $\mathrm{CH}$ foram semelhantes devido à maior reatividade da NS em comparação com a SA. Na pesquisa realizada por ANDRADE et al. [6] foi observado ao substituir o cimento Portland por 3\%NS, $10 \% \mathrm{SA}$ ou $10 \% \mathrm{SA}+3 \% \mathrm{NS}$ houve redução no teor de $\mathrm{CH}$. Quanto maior foi o teor de substituição, menor foi o teor de $\mathrm{CH}$ aos 3, 7 e 28 dias de hidratação. Aos 91 dias o teor de $\mathrm{CH}$ da pasta com 10\% de SA foi igual ao teor de $\mathrm{CH}$ da pasta com $3 \%$ de NS. Os autores relataram que a atividade pozolânica da NS foi observada com maior acentuação na primeira idade avaliada (3 dias de hidratação) e da SA aos 7 dias de hidratação.

Tabela 5: Índice de C-S-H e índice de CH obtidos através do ensaio de termogravimetria das pastas aos 1, 3, 7 e 28 dias de hidratação.

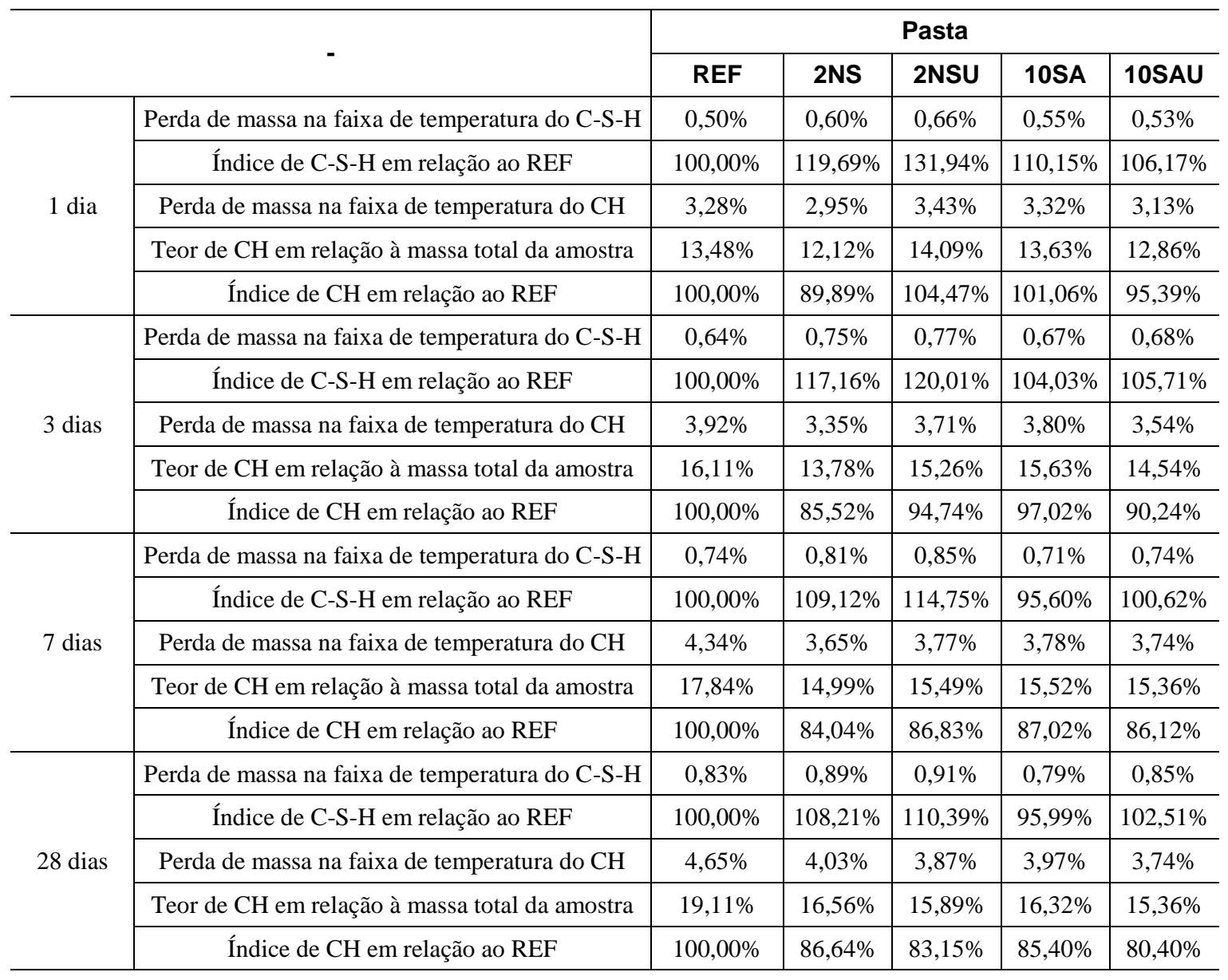

\subsection{Espectroscopia no infravermelho (FTIR)}

Na figura 8 são apresentados os resultados do ensaio de espectroscopia no infravermelho aos 28 dias. A banda no comprimento de onda de $3644 \mathrm{~cm}^{-1}$ é relativa aos grupos livres de $\mathrm{OH}$ referentes ao $\mathrm{CH}$ e a banda com comprimento de onda de $975 \mathrm{~cm}^{-1}$ está relacionada com as ligações Si-O correspondentes ao C-S-H [49]. Dessa forma, na figura 8(a) é possível observar que as pastas REF e 10SA apresentaram maior teor de CH e as pastas 2NS, 2NSU e 10SAU apresentaram menor teor de $\mathrm{CH}$. Na figura 8(b) observa-se que as pastas 2NS e 2NSU apresentaram maior teor de C-S-H, seguidas pela pasta 10SAU e pelas pastas 10SA e REF com intensidades menores. Esse comportamento é justificado pela reação pozolânica entre o $\mathrm{CH}$ e a sílica ativa ultrasonicada ou a nanossílica coloidal tanto em seu estado natural como ultrasonicada que consumiu $\mathrm{CH}$ para formação de mais C-S-H, ratificando os resultados análise termogravimétrica mostrados na tabela 5.

Esses resultados corroboram com SINGH et al. [10], que estudaram pastas de cimento com $3 \%$ de NS ou com $3 \%$ de SA com relação a/agl= 0,35 . Os resultados de espectroscopia no infravermelho das pastas aos 28 dias de hidratação mostraram que ao substituir o cimento Portland pela NS ou pela SA houve redução da intensidade da banda referente ao $\mathrm{CH}$ devido à reação pozolânica desses materiais. Essa redução foi mais 
acentuada na pasta com NS do que na pasta com SA devido à maior reatividade da NS pela maior superfície específica de suas partículas.

(a)

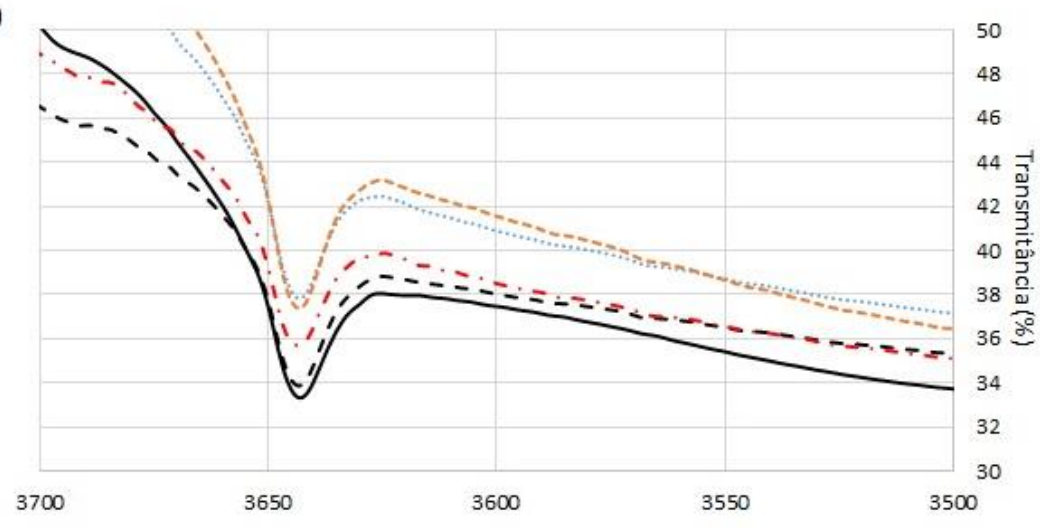

Comprimento de onda $\left(\mathrm{cm}^{-1}\right)$

(b)

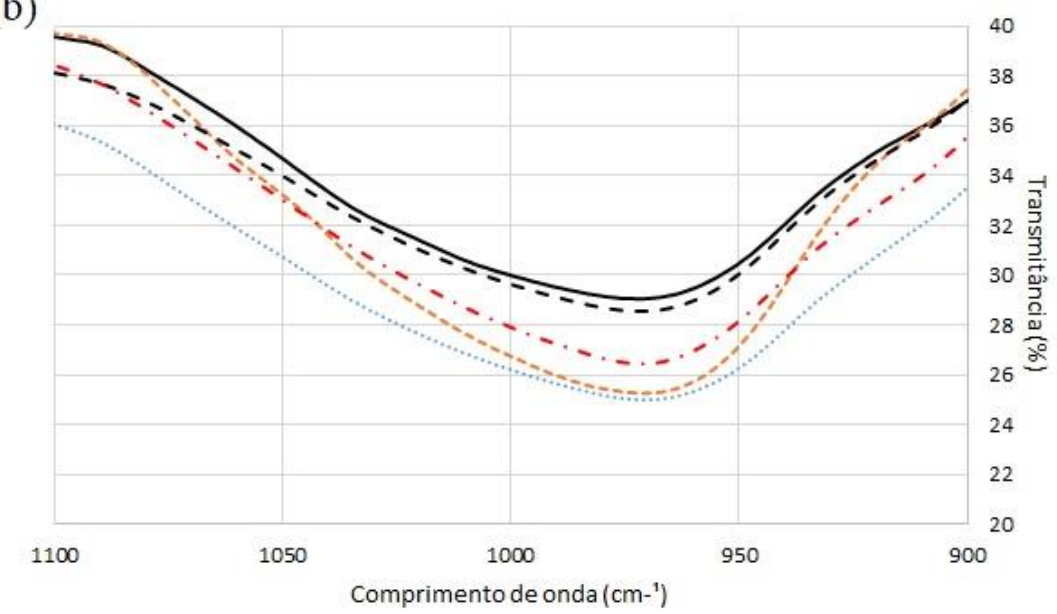

Figura 8: Espectros de infravermelho das pastas aos 28 dias de hidratação (a) região correspondente ao $\mathrm{CH}$; (b) região referente ao C-S-H.

\subsection{Porosimetria por intrusão de mercúrio (PIM)}

Os resultados do volume de mercúrio incrementado intrudido e do volume acumulado de intrusão das pastas aos 28 dias obtidos no ensaio de porosimetria por intrusão de mercúrio são mostrados na figura 9. De acordo com os resultados apresentados anteriormente, esperava-se que as pastas 2NS e 2NSU resultassem em estruturas porosas semelhantes, pois foi constatado que o processo de ultrasonicação da NS coloidal não influenciou as reações de hidratação das pastas aos 28 dias de hidratação. Foi possível observar que o processo de ultrasonicação da SA refinou a estrutura porosa da pasta 10SAU em comparação com a pasta 10SA. Além disso, as pastas REF e 10SA apresentaram diâmetros médios dos poros semelhantes. Observou-se que as pastas com NS coloidal tiveram menor volume acumulado intrudido, seguidas pela pasta 10SAU e pelas pastas REF e 10SA que tiveram volumes acumulados intrudidos semelhantes entre si.

De acordo com FLORES et al. [2], a incorporação da NS em pastas de cimento resulta em uma rede porosa mais refinada do que a incorporação da SA. Quanto menor o tamanho dos materiais cimentícios suplementares, maior refinamento da estrutura porosa. Esse mesmo comportamento foi observado no presente estudo, pois a NS coloidal (ultrasonicada ou não) resultou no maior refinamento da estrutura porosa das pastas, o que pode ser justificado pelo efeito de nucleação e pela alta reatividade da NS [50].

A pasta contendo SA ultrasonicada resultou em maior refinamento dos poros em comparação com a pasta REF, ao contrário da pasta com SA em seu estado natural que apresentou distribuição do tamanho dos poros semelhante à pasta REF. Esse resultado diverge do estudo realizado por BHATTACHARYA e HARISH [16], que observaram menor porosidade de todas as pastas com diferentes teores de SA quando compa- 
radas com a pasta referência. Esse comportamento divergente pode ser explicado pelo menor tamanho das partículas de SA utilizadas na pesquisa de BHATTACHARYA e HARISH [16].

De acordo com BARBHUIYA et al. [51], a utilização de sílica ativa em seu estado natural (aglomerada) em materiais cimentícios reduz a eficácia da reação pozolânica e pode contribuir para a formação de pequenas áreas de alta porosidade. Dessa forma, esse comportamento justifica os resultados apresentados.
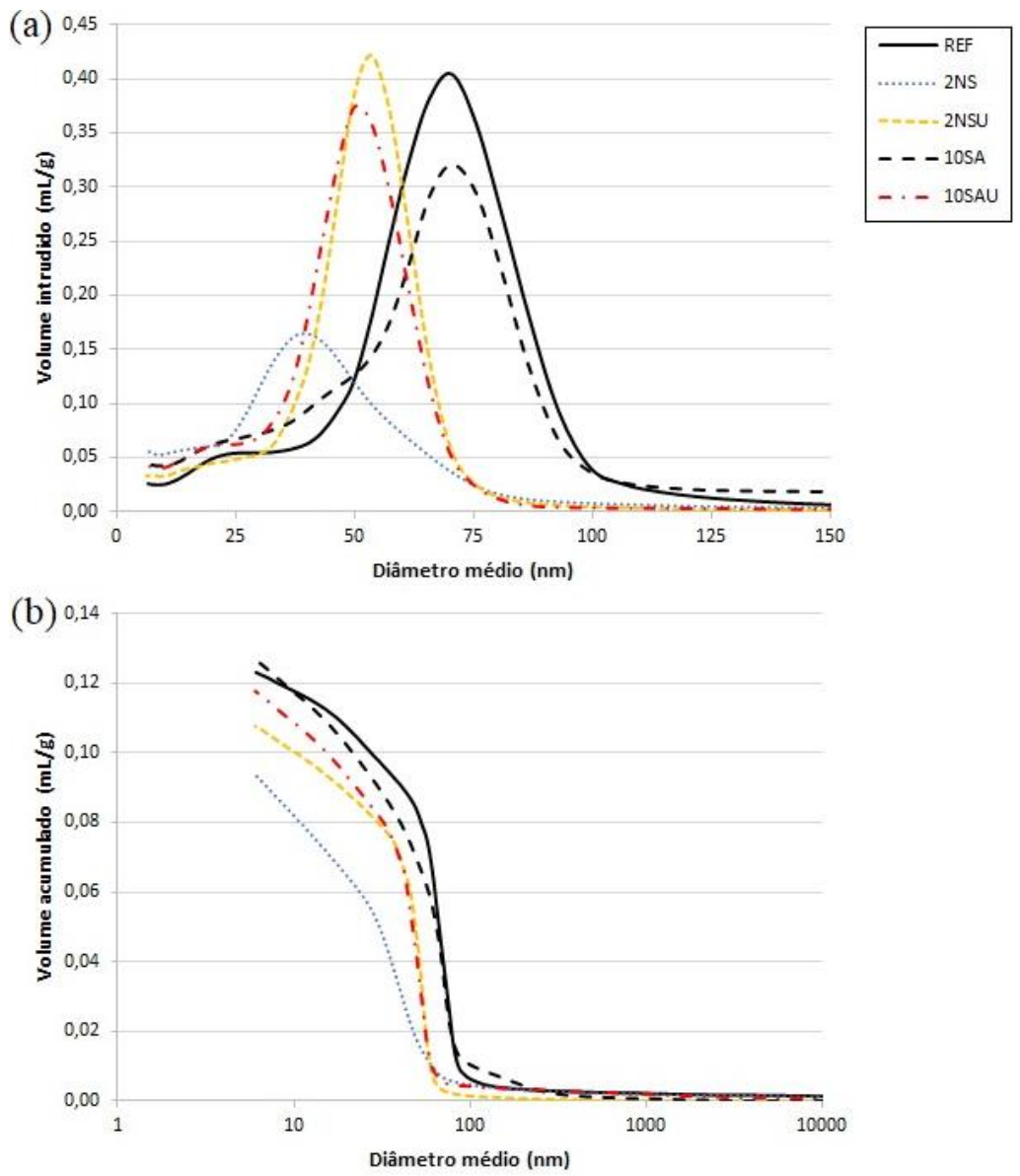

Figura 9: (a) Volume incrementado intrudido; (b) volume acumulado de intrusão nas pastas aos 28 dias.

\section{CONCLUSÕES}

Com base nos resultados obtidos através dos ensaios realizados, foi possível concluir que:

- A utilização de apenas $2 \%$ de nanossílica coloidal foi mais eficiente que a utilização de $10 \%$ da sílica ativa no aumento da resistência à compressão e no refinamento da estrutura porosa das pastas.

- Não houve efeito significativo ao ultrasonicar a nanossílica coloidal quanto ao teor de aditivo superplastificante necessário para manter a mesma consistência entre as pastas. De mesmo modo, não houve influência do processo de ultrasonicação da nanossílica coloidal na resistência à compressão, no consumo de $\mathrm{CH}$ e na formação de $\mathrm{C}-\mathrm{S}-\mathrm{H}$ e na estrutura porosa das pastas.

- O processo de ultrasonicação da sílica ativa resultou no aumento da demanda de aditivo superplastificante para manter a mesma consistência entre as pastas, aumentou a resistência à compressão, aumentou o consumo de $\mathrm{CH}$ para formação de mais $\mathrm{C}-\mathrm{S}-\mathrm{H}$ e refinou a estrutura porosa das pastas.

Dessa forma, os parâmetros de ultrasonicação utilizados foram eficientes para dispersar a sílica ativa, formando mais C-S-H e densificando a microestrutura das pastas de cimento, porém não foi eficiente para realizar a dispersão total da nanossílica coloidal que estava parcialmente dispersa.

\section{SUGESTÕES PARA TRABALHOS FUTUROS}

Ressalta-se a importância dos seguintes estudos futuros:

- Avaliar a influência da ultrasonicação, sob diferentes parâmetros, da sílica ativa e da nanossílica co- 
loidal nas propriedades reológicas (tensão de escoamento e viscosidade) e na microestrutura de pastas de cimento Portland ao longo do tempo;

- Investigar o efeito da ultrasonicação sob diferentes parâmetros da sílica ativa e da nanossílica coloidal quanto à durabilidade do concreto de alto desempenho (reação álcali-agregado, carbonatação e ação de íons cloreto);

- Desenvolver estudos sobre outros métodos que facilitem a dispersão da sílica ativa e da nanossílica pela indústria;

- Estudar o efeito da ultrasonicação conjunta da sílica ativa e da nanossílica utilizadas em substituição parcial ao cimento Portland na microestrutura de pastas ternárias.

\section{AGRADECIMENTOS}

Os autores agradecem ao Conselho Nacional de Desenvolvimento Científico e Tecnológico (CNPq), à Coordenação de Aperfeiçoamento de Pessoal de Nível Superior (CAPES) e à Fundação de Apoio à Pesquisa do Distrito Federal (FAPDF) pelos apoios financeiros para a realização de pesquisas no Programa de Pósgraduação em Estruturas e Construção Civil da Universidade de Brasília (PECC/UnB).

\section{BIBLIOGRAFIA}

[1] BELAPOUR, M., JOSHAGHANI, A., ALTHOEY, F., "Nano-SiO2 contribution to mechanical, durability, fresh and microstructural characteristics of concrete: A review", Construction and Building Materials, v. 181, pp. 27-41, 2018.

[2] FLORES, Y. C., CORDEIRO, G. C., TOLEDO FILHO, R. D., et al., "Performance of Portland cement pastes containing nano-silica and different types of silica", Construction and Building Materials, v. 146, pp. 524-530, 2017.

[3] FENG, L., ZHAO, P., WANG, Z., et al., "Improvement of mechanical properties and chloride ion penetration resistance of cement pastes with the addition of pre-dispersed silica fume", Construction and Building Materials, v. 182, pp. 483-492, 2018.

[4] ABD-EL-ENEIN, S. A., EL-KADY, G., EL-SOKKARY, T. M., et al., "Physico-mechanical properties of composite cement pastes containing silica fume and fly ash", HBRC Journal, v. 11, pp. 7-15, 2015.

[5] RÊGO, J. H. S., ROJAS, M. F., TERRADES, A. M., et al., "Effect of Partial Substitution of Highly Reactive Mineral Additions by Nanosilica in Cement Pastes", Journal of Materials in Civil Engineering, v. 31, pp. 040183601-0401836011, 2019.

[6] ANDRADE, D. S., RÊGO, J. H. S., MORAIS, P. C., et al., "Investigation of C-S-H in ternary cement pastes containing nanosilica and highly-reactive supplementary cementitious materials (SCMs): Microstructure and strength", Construction and Building Materials, v. 198, pp. 445-455, 2019.

[7] GARCIA, D. C. S., SOARES, M. M. N. S., BEZERRA, A. C. S., et al., "Microstructure and hardness of cement pastes with mineral admixture", Revista Matéria, v. 22, pp. 1-10, 2017.

[8] ASSOCIAÇÃO BRASILEIRA DE NORMAS TÉCNICAS. NBR 13956-1: Sílica ativa para uso com cimento Portland em concreto, argamassa e pasta - Parte 1: Requisitos. Rio de Janeiro, 2012.

[9] AÏTCIN, P. C., Concreto de alto desempenho, 1 ed., São Paulo, PINI, 2000.

[10] SINGH, L. P., GOEL, A., BATTACHARYYA, S. K., et al., "Hydration studies of cementitious materials using sílica nanoparticles", Journal of Advanced Concrete Technology, v. 13, pp. 345-354, 2015.

[11] MOON, J., MAHMORD, M., REDA, T., et al., "Investigation of pozzolanic reaction in nanosilicacement blended pastes based on solid-state kinetic models and 29Si MAS NMR", Materials, v. 99, pp. 1-12, 2016.

[12] HOU, P., KAWASHIMA, S., KONG, D., et al., "Modification effects of colloidal nanoSiO2 on cement hydration and its gel property", Composites: Part B, v. 45, pp. 440-448, 2013.

[13] FERNANDEZ, J. M., DURAN, A., NAVARRO-BLASCO, I., et al., I., "Influence of nanosilica and polycarboxylate ether superplasticizer on the performance of lime mortars", Cement and Concrete Research, v. 43 , pp. 12-24, 2013.

[14] GUERRERO, A. M., GAITERO, J. J., QUINONES, G. P. A., et al., "Multi-scale analysis of cement pastes with nanosilica addition", Advances in Cement Research, v. 26, pp. 271-280, 2014. 
[15] AHARI, R. S., ERDEM, T. K., RAMYAR, K., "Effect of various Supplementary cementitious materials on rheological properties of self-consolidating concrete", Construction and Building Materials, v. 75, pp. 8998, 2015.

[16] BHATTACHARYA, M., HARISH, K. V., "An integrated approach for studying the hydration of portland cement systems containing silica fume", Construction and Building Materials, v. 188, pp. 1179-1192, 2018.

[17] BOLHASSANI, M., SAMANI, M., "Consequences of colloidal nanosilica specific surfasse on its performance in concrete", Advances in Civil Engineering Materials, v. 4, pp. 80-93, 2015.

[18] ROMANO, R. C. O., SCHREURS, H., JOHN, V. M.; et al., "Influência da técnica de dispersão nas propriedades da sílica ativa", Cerâmica, v. 54, pp. 456-461, 2008.

[19] ZHANG, Z., ZHANG, B., YAN, P., "Comparative study of effect of raw and densified sílica fume in paste, mortar and concrete", Construction and Building Materials, v. 105, pp. 82-93, 2016.

[20] CAI, Y., HOU, P., CHENG, X., et al., "The effects of nanoSiO2 on the properties of fresh and hardened cement-based materials through its dispersion with silica fume", Construction and Building Materials, v. 148, pp. 770-780, 2017.

[21] RECHES, Y., THOMSON, K., HELBING, M., et al., "Agglomeration and reactivity of nanoparticles of $\mathrm{SiO} 2, \mathrm{TiO} 2, \mathrm{Al} 2 \mathrm{O} 3, \mathrm{Fe} 2 \mathrm{O} 3$, and clays in cement pastes and effects on compressive strenght at ambiente and elevated temperatures", Construction and Building Materials, v. 167, pp. 860-873, 2018.

[22] RODRÍGUEZ, E. D., SORIANO, L., PAYÁ, J., et al., "Increase of the reactivity of densified silica fume by sonication treatment", Ultrasonics Sonochemistry, v. 19, pp. 1099-1107, 2012.

[23] JAFARI, V., ALLAHVERDI, A., VAFAEI, M., "Ultrasound-assisted synthesis of colloidal nanosilica from silica fume: Effect of sonication time on the properties of product", Advanced Powder Technology, v. 25, pp. 1571-1577, 2014.

[24] LI, X., KORAYEM, A. H., LI, C., et al., "Incorporation of graphene oxide and silica fume into cement paste: A study of dispersion and compressive strength", Construction and Building Materials, v. 123, pp. 327-335, 2016

[25] SHAO, D., DIAO, J., WANG, L., LI, L., "Effect of surface modification on the compressive properties of silica fume/polyurethane composites", Journal of Polymer Engineering, pp. 1-6, 2016.

[26] ZAPATA, L. E., PORTELA, G., SUÁREZ, O. M., et al., "Rheological performance and compressive strength of superplasticized cementitious mixtures with micro/nano-SiO2 additions", Construction and Building Materials, v. 41, pp. 708-716, 2013.

[27] DU, H., DU, S., LIU, X., "Durability performances of concrete with nano-silica", Construction and Building Materials, v. 73, pp. 705-712, 2014.

[28] TOBÓN, J. I., PAYÁ, J., RESTREPO, O. J., "Study of durability of Portland cement mortars blended with silica nanoparticles", Construction and Building Materials, v. 80, pp. 92-97, 2015.

[29] BARKOUlA, N. M., IOANNOU, C., AGGELIS, D. G., et al., "Optimization of nano-silica's addition in cement mortars and assessment of the failure process using acoustic emission monitoring", Construction and Building Materials, v. 125, pp. 546-552, 2016.

[30] GHAFOORI, N., BATILOV, I., NAJIMI, M., "Influence of dispersion methods on sulfate resistance of nanosilica-contained mortars", Journal of Materials in Civil Engineering, v. 29, pp. 1-13, 2017.

[31] COLlODETTI, G., Desenvolvimento de híbrido sílica/siloxano para uso como aditivo em pastas de cimento, Tese de D.Sc., UFSC, Florianópolis, SC, Brasil, 2013.

[32] LUZ, G., Avaliação da forma de adição de nanossílica nas propriedades mecânicas de pastas de cimento, Trabalho de conclusão de curso, UFSC, Florianópolis, SC, Brasil, 2015.

[33] ASSOCIAÇÃO BRASILEIRA DE NORMAS TÉCNICAS. NBR 16697: Cimento Portland - Requisitos. Rio de Janeiro, 2018.

[34] ASSOCIAÇÃO BRASILEIRA DE NORMAS TÉCNICAS. NBR 13956-1: Sílica ativa para uso com cimento Portland em concreto, argamassa e pasta - Parte 1: Requisitos. Rio de Janeiro, 2012.

[35] ASSOCIAÇÃO BRASILEIRA DE NORMAS TÉCNICAS. NBR 11768: Aditivos químicos para concreto de cimento Portland - Requisitos. Rio de Janeiro, 2011.

[36] KANTRO, D. L., "Influence of Water-Reducing Admixtures on Properties of Cement Paste - A Miniature Slump Test”, Cement, Concrete and Aggregates, v. 2, pp. 95-102, 1980. 
[37] CHEN, Y., DENG, Y., LI, M., "Influence of nano-sio2 on the consistency, setting time, early-age strength, and shrinkage of composite cement pastes", Advances in Materials Science and Engineering, pp. 18, 2016.

[38] GHODDOUSI, P., JAVID, A. A. S., ZAREECHIAN, M., et al., "Physical and chemical effects of siliceous particles at nano, micro, and macro scales on properties of self-consolidating mortar overlays", Construction and Building Materials, v. 189, pp. 1140-1154, 2018.

[39] LI, L. G., HUANG, Z. H., ZHU, J., et al., "Synergistic effects of micro-silica and nano-silica on strength and microstructure of mortar", Construction and Building Materials, v. 140, pp. 229-238, 2017.

[40] ZHANG, X., DU, X., ZHAO, X., et al., "The synergistic effect of nano-SiO2 with silica fume in cement-based material”, Journal of Sustainable Cement-Based Materials. v. 6, pp. 267-279, 2016.

[41] ALONSO-DOMÍNGUEZ, D., ÁLVAREZ-SERRANO, I., REYES, E., et al., "New mortars fabricated by electrostatic dry deposition of nano and microsilica additions: Enhanced properties", Construction and Building Materials, v. 135, pp.186-193, 2017.

[42] ASSOCIAÇÃO BRASILEIRA DE NORMAS TÉCNICAS. NBR 16606: Cimento Portland - Determinação da pasta de consistência normal. Rio de Janeiro, 2017.

[43] ASSOCIAÇÃO BRASILEIRA DE NORMAS TÉCNICAS. NBR 7215: Cimento Portland - Determinação da resistência à compressão. Rio de Janeiro, 1996.

[44] SCRIVENER, K., SNELLINGS, R., LOTHENBACH, B., A practical guide to microstructural analysis of cementitious materials, 1 ed., New York, Taylor e Francis Group, 2016.

[45] TAYLOR, H. F. W., Cement Chemistry. 2. ed., London, Thomas Telford, 1997.

[46] SENFF, L., HOTZA, D., REPETTE, W. L., "Comportamento reológico de pastas de cimento com adição de sílica ativa, nanossílica e dispersante policarboxílico”, Revista Matéria, v. 15, pp. 12-20, 2010.

[47] HARUEHANSAPONG, S., PULNGERN, T., CHUCHEEPSAKUL, S., "Effect of the particle size of nanosilica on the compressive strength and the optimum replacement content of cement mortar containing nano-SiO2", Construction and Building Materials, v. 50, pp. 471-477, 2014.

[48] KHALOO, A., MOBINI, M. H., HOSSEINI, P., "Influence of different types of nano-SiO2 particles on properties of high-performance concrete", Construction and Building Materials, v. 113, pp. 188-201, 2016.

[49] BUSTOS, A. M. G., QUIÑONES, G. P. Á., REDONDO, J. J. G., et al., "Multi-scale analysis of cement pastes with nanosilica addition", Advances in Cement Research, v. 26, pp. 271-280, 2014.

[50] LAND, G., STEPHAN, D., "The influence of nano-silica on the hydration of ordinary Portland cement", Journal of Materials Science, v. 47, pp. 1011-1017, 2012.

[51] BARBHUIYA, S., CHOW, P., DAS, A., "Nanomechanical properties of cement paste containing silica fume", In: Proceedings of International Conference on Architecture and Civil Engineering (ICAACE'14), pp. 92-97, Dubai, Dec. 2014.

\section{ORCID}

Yuri Sotero Bomfim Fraga João Henrique da Silva Rêgo Valdirene Maria Silva Capuzzo Daniel da Silva Andrade https://orcid.org/0000-0002-0426-4615

https://orcid.org/0000-0001-9060-2010

https://orcid.org/0000-0001-6923-7565

https://orcid.org/0000-0002-4945-2468 